\title{
Teaching academic software via YouTube videos in the Covid- 19 pandemic: potential applications for learning development
}

\author{
Lee Fallin \\ University of Hull, UK
}

Keywords: learning development; YouTube; software instruction; software training; online video; Covid-19.

\section{The challenge}

The Skills Team at the University of Hull not only facilitate learning development support, but also support the development of information, digital, research, and visual literacies. An important part of the Team's remit is the support of core academic and research software packages, including bibliographic management tools like EndNote and RefWorks as well as data analysis packages like NVivo and SPSS. These software packages are shown to have a significant positive impact on academic and research productivity, especially when individuals are trained to use the software (Basak, 2015). This is because software can automate time-consuming processes, increase researcher efficiency (Basak, 2015), and perform computations that are nearly impossible without software. Furthermore, the Skills Team's support of this software allows a holistic service to be offered to students and staff. It also provides the opportunity to embed learning development throughout the service. For example, bibliographic software workshops consider the academic practices around citations. This supports students to develop their knowledge of how to cite and, more importantly, the reasons they need to. Another example can be seen in supporting the use of Microsoft Word for writing - highlighting how effective use of the Review ribbon can support proofreading and how the Navigation Pane can support revision. These examples show how Skills Team software support is never abstracted from the literacy practices they support.

The Covid-19 pandemic, however, presented a significant problem. Traditional instruction for software was reliant on face-to-face courses based in computer rooms (Kalpokaite and 
Radivojevic, 2020). This is not easily translated online. Whereas face-to-face classes allow instructors to move around the classroom and check-in on individual students or help those falling behind, online synchronous teaching does not have this affordance. It requires screen sharing or breakouts, which disrupt the flow of a class or require additional instructors to manage. In face-to-face classes, students can use their own computer while also watching the instructor's demonstration. Unless students have two screens, this is impossible to achieve in a live online class, especially with the added challenge of connection speed and the potential for technical problems (Kalpokaite and Radivojevic, 2020).

\section{The response}

To continue offering the software support service, the Skills Team decided to expand the use of video. The Team had always previously produced the workshop content for the university library's YouTube account, but the pandemic provided the perfect opportunity for this to become a primary outlet, as opposed to something worked on in spare time. We chose YouTube as it is a familiar platform offering ease of access across different devices. Videos are well suited for software instruction in comparison to synchronous online sessions as users can play, pause, and rewind as needed. It also allows more in-depth content to be covered as time is more flexible (Walker, Row and Dolence, 2007), allowing us to go beyond what would be covered in a two-hour workshop. This is because it provides optionality in learning. A student could, for example, skip the EndNote video if they only use in-text citation formats. They could then use that time to learn of more advanced aspects of the software.

While videos were not a new format for the Skills Team, their usage really exploded in the pandemic (see Figure 1). This was not because the Team produced more videos. In fact, the YouTube channel published 100 videos in 2018, compared to 101 videos of similar length in 2020. Moreover, it was due to a substantial increase in video views, with the significant increase correlating to the start of the first lockdown in the UK. This applied to both old and new videos, although more recent videos performed better. Interestingly, there was no significant dip in viewing over summer. This potential reflects the delayed progression of many students due to personal circumstances in the pandemic or suspended assessments by institutions (Watermeyer et al., 2021). Even though there were 
periods of more regular face-to-face operation between the lockdowns, video popularity has remained high.

Figure 1. YouTube views (August 2019-May 2021).

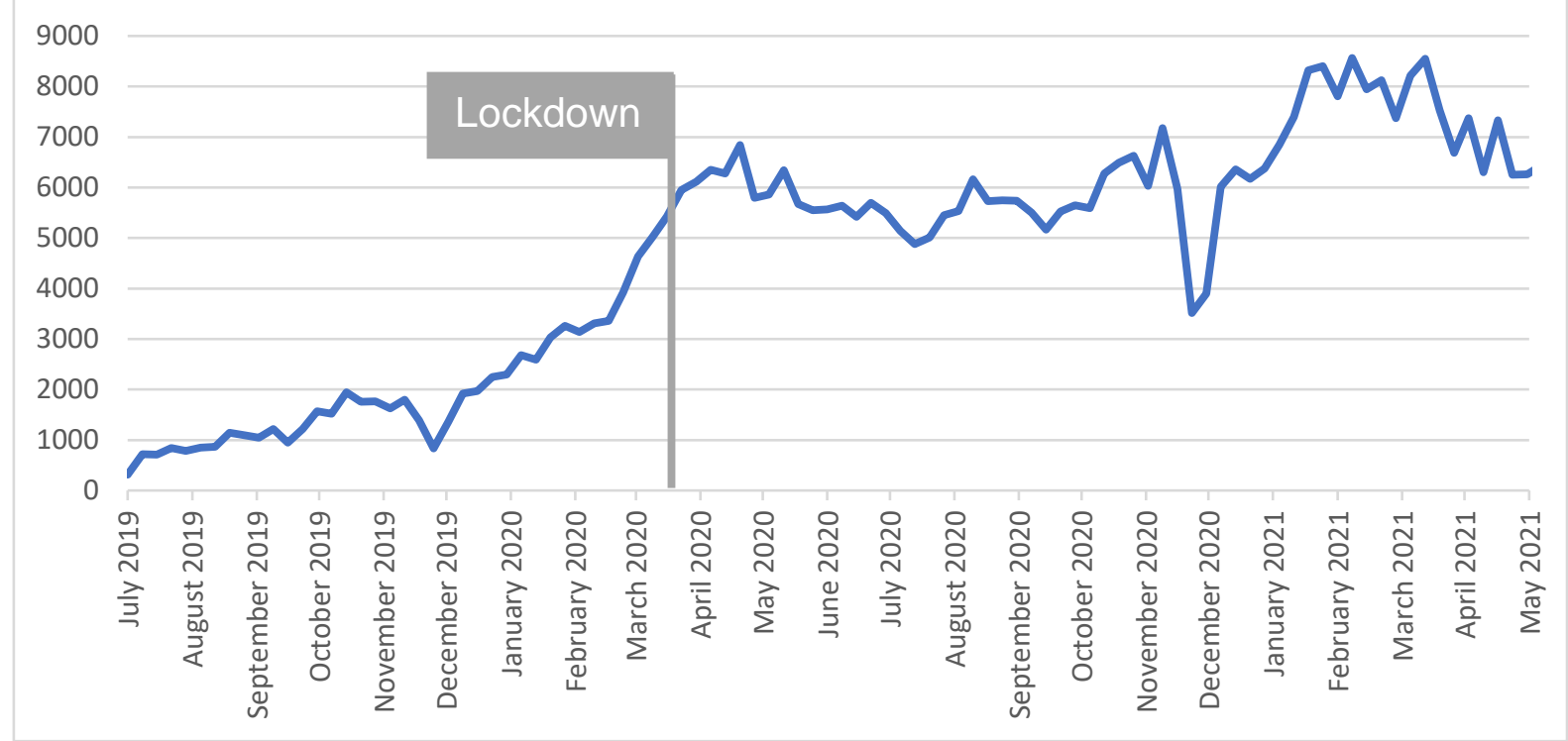

\section{Recommendations}

Software instruction as an approach to develop academic literacies has always been an important aspect of the Skills Team's work. I was concerned that the Covid-19 pandemic put this aspect of our service at risk, especially given the challenges of delivering this support synchronously. However, as demonstrated above, the production of YouTube videos has enabled this to continue. It is no surprise that other studies (Rodríguez-Moreno et al., 2021) have advocated using YouTube to improve students' digital literacies.

Research has also shown that YouTube can support students to develop simple skills and enhance student engagement (Fleck et al., 2014; Almobarraz, 2018). Despite this, the videos the Skills Team had produced for the university library's YouTube Channel did not come into frequent use until the Covid-19 pandemic and the associated lockdowns. The fact that this usage did not drop when campus access returned leads me to think it will continue to be a significant part of the Skills Team's provision moving forwards. Online videos are more than just a mechanism to ensure the service continued. They offered students the flexibility to access support any time, any day. YouTube videos can also be watched, paused, and re-watched as required by students - even after they graduate. 
When considering what comes next, I am interested in further experimenting with the use of video for learning development. In addition to supporting software, there is the potential to support more traditional learning development literacies like critical thinking. So far, I have taken the opportunity to trial this through a series of seven YouTube videos (University of Hull, 2020). While these videos are still a new resource, the usage pattern of these videos has grown monthly since they were first published in July 2020. I have also used them in my own practice, sending them to students ahead of an appointment. This has allowed us to focus appointment time on contextualising such academic literacies into the students' own disciplinary context. On this basis, I think video support may have an exciting place in learning development, helping us focus on more quality encounters with students.

\section{References}

Almobarraz, A. (2018) 'Utilization of YouTube as an information resource to support university courses', The Electronic Library, 36(1), pp.71-81. https://doi.org/10.1108/EL-04-2016-0087.

Basak, S. K. (2015) 'Analysis of the impact of NVivo and EndNote on academic research productivity', International Journal of Educational and Pedagogical Sciences, 9(9), pp.3237-3242. https://doi.org/10.5281/zenodo.1109862.

Fleck, B. K., Beckman, L. M., Sterns, J. L. and Hussey, H. D. (2014) 'YouTube in the classroom: helpful tips and student perceptions', Journal of Effective Teaching, 14(3), pp.21-37. https://doi.org/10.1108/EL-04-2016-0087.

Kalpokaite, N. and Radivojevic, I. (2020) 'Teaching qualitative data analysis software online: a comparison of face-to-face and e-learning ATLAS.ti courses', International Journal of Research \& Method in Education, 43(3), pp. 296-310. https://doi.org/10.1080/1743727X.2019.1687666.

Rodríguez-Moreno, J., Ortiz-Colón, A. M., Cordón-Pozo, E. and Agreda-Montoro, M. (2021) 'The influence of digital tools and social networks on the digital competence 
of university students during COVID-19 pandemic', International Journal of Environmental Research and Public Health, 18(6), pp.2835. https://doi.org/10.3390/ijerph18062835.

University of Hull (2020) Critical thinking \& writing [video workshop]. Available at: https://libguides.hull.ac.uk/workshops/video-critical (Accessed: 18 May 2021).

Walker, T. B., Row, J. S. and Dolence, T. (2007) 'Teaching and supporting EndNote at the University of Tennessee: designing online alternatives to high demand classes', The Electronic Journal of Academic and Special Librarianship, 8(2). Available at: Teaching and Supporting EndNote at the University of Tennessee: Designing Online Alternatives to High Demand Classes (unl.edu) (Accessed: 29 June 2021).

Watermeyer, R., Crick, T., Knight, C. and Goodall, J. (2021) 'COVID-19 and digital disruption in UK universities: afflictions and affordances of emergency online migration', Higher Education, 81(3), pp.623-641. https://doi.org/10.1007\%2Fs10734-020-00561-y.

\section{Author details}

Lee Fallin is an Academic and Library Specialist (Learning Developer) at the University of Hull with a specialism in academic and digital literacies. His research interests focus on the intersections between education and geography, inclusive of physical and digital spaces. 